\title{
LUT Assisted Adaptive Overcurrent Protection of Reconfigurable Microgrids
}

\author{
O.V.Gnana Swathika*t, S. Hemamalini** \\ *School of Electrical Engineering, VIT University Chennai \\ **School of Electrical Engineering, VIT University Chennai \\ ¥VIT University Chennai, Tel: +91-04439931241, \\ (gnanaswathika.ov@vit.ac.in)
}

Received: 16.01.2018 Accepted:05.02.2018

\begin{abstract}
Microgrids are the key solution to handle the growing technical, environmental and economical concerns of existing power system networks. The purpose of this paper is to develop an intelligent and adaptive overcurrent protection system for a microgrid. This system is capable of monitoring, protecting and controlling the microgrid. A look up table is created and maintained at the central protection system of the microgrid, which has details of normal and faulted current in all feeders for various topologies of the microgrid system. It has the optimized values for time dial setting and operating time of relays for faults at a specific location in the reconfigured system, which is generated using Dual Simplex algorithm. Hence the Central Protection System aids in providing suitable overcurrent relay coordination to the microgrid, which may incur reduced network disconnection. The hardware prototype of the Central Protection System is realized, tested and validated on a balanced 21-bus microgrid system.
\end{abstract}

Keywords Look up Table, Adaptive Protection, Overcurrent relay coordination, Dual Simplex algorithm.

NOMENCLATURE

\begin{tabular}{|c|c|}
\hline LUT & Look-Up-Table \\
\hline RES & Renewable Energy Systems \\
\hline CPS & Central Protection System \\
\hline DG & Distributed Generators \\
\hline MLP & Multilayer Perceptrons \\
\hline DOCR & Directional overcurrent relays \\
\hline FPGA & Field-programmable gate array \\
\hline OCR & Overcurrent Relay \\
\hline TLBO & Teaching Learning Based Optimization \\
\hline IED & Intelligent Electronic Devices \\
\hline DER & Distributed Energy Resources \\
\hline IIDG & Inverter interfaced Distributed Generator \\
\hline $\mathrm{t}_{\mathrm{opj}}$ & $\begin{array}{l}\text { Operating time for the primary relay for a } \\
\text { fault at location ' } j \text { ' }\end{array}$ \\
\hline$\alpha, \lambda, \gamma$ & Constants of the relay \\
\hline IDMT & Inverse Definite Minimum Time \\
\hline PSM & Plug Setting Multiplier \\
\hline TMS & Time Multiplier Setting \\
\hline$t_{\text {opjmin }}$ & $\begin{array}{l}\text { minimum time required for operation of } \\
\text { the relay for a fault at ' } \mathrm{j} \text { ' }\end{array}$ \\
\hline$t_{\text {opjmax }}$ & $\begin{array}{l}\text { maximum time required for operation of } \\
\text { the relay for a fault at ' } \mathrm{j} \text { ' }\end{array}$ \\
\hline CTI & Coordination Time Interval \\
\hline$t_{\text {opjb }}$ & $\begin{array}{l}\text { the operating time of the backup relay for a } \\
\text { fault at ' } \mathrm{j} \text { ' }\end{array}$ \\
\hline
\end{tabular}

GMFDS Grid Monitoring and Fault Detection System

CT Current Transformer

LPP Linear Programming Problem

MUX Multiplexer

CB Circuit Breaker

FSS Fault Switching Subsystem

$\mathrm{I}_{\mathrm{f}} \quad$ Fault Current in Amperes

CT Current Transformer

RS Relay Setting

FCB Fault Capturing Block

\section{Introduction}

Microgrid is a distribution level network which is a collection of generators, including renewable energy sources, loads and storage modules. It maybe treated as a load or source with regard to the utility grid [1]. Few critical reasons that cause an inclination to DG penetration are advancement in DG technologies, constraints in constructing more transmission lines, increasing demand for highly reliable electricity and electricity market liberalization [2-3]. Protection of the microgrid becomes challenging and conventional protection schemes are not applicable due to fault current magnitude variation, dynamic nature of microgrid [4] and DG intervention [5-6].

Digital relays interfaced to circuit breakers are suggested as a solution for fault current magnitude issues [7]. 
Communication is a promising component in the nextgeneration hybrid microgrid protection system. Two-way communications are the basic infrastructure required for accommodating distributed renewable energy generation [8]. MLP neural networks are utilized to protect DG penetrated distribution system [9]. Due to varying topology of microgrid network, it is necessary to monitor the microgrid continuously and alter the protection schemes appropriately [10-11]. Communication based directional overcurrent relays are implemented with the assistance of inter-tripping and blocking transfer functions. This scheme guarantees appropriate selectivity for a specific microgrid topology [12]. Neural network based fault location algorithms are proposed for the design of protection schemes in microgrids. But this system consumes more time and is complex [13-14]. A three-phase monitoring tool based on impedance measurement is employed in microgrid network. This tool is not yet tested on grid with substantial changes like islanding of network. Fast transients are easily detected using this monitoring technique [15]. A hybrid scheme of protecting microgrid is realized using differential and adaptive protection scheme. It results in reliable results and involves less communications cost [16]. A central controller runs the real-time analysis on the critical information obtained from the field Intelligent Electronic Devices in the power system network and communicates via IEC 61850 [17-18]. The configurations of communication-assisted relays are adaptively set, since the fault current sensed in gridconnected and islanded modes are significantly different [1920]. Different fault monitoring and protection systems are suggested in literature, but without much emphasis on fault isolation which may involve reduced load disconnection in a reconfigurable microgrid.

DOCRs are a key solution in handling the aforementioned challenges in microgrid. There are applications in which multiple DOCR settings are followed for a network [21]. Numerical overcurrent relay [22] protection using FPGA is a strategy that may be used in islanded microgrid. Accuracy and speed in isolating faults are the features of this relay [23]. In OCR coordination, the optimization of TMS is done using algorithms like: genetic [24], dual simplex, TLBO [25], modified relay coded genetic [26], informative differential evolution [27], bio-geography based [28] and chaotic firefly [29]. In a dynamic grid, graph theory algorithms are incorporated for load flow analysis [30], and for minimizing active power flow [31].

Adaptive protection is a key solution to microgrid protection. This protection scheme monitors the operating state of microgrid continuously and assigns the suitable relay settings. The communication protocols are employed in large distribution networks for adaptively assigning the relay settings. The fault current coefficient is a deciding parameter in altering the relay hierarchy to facilitate adaptive relay coordination in microgrid. Hailuoto island, Finland incorporates the adaptive protection scheme, where the centralized controller is kept informed by the field IED using IEC 61850 communication protocol. The IEC61850 is control architecture with adaptive control strategy for the microgrid. During faults, IEEE Standard 1547 protocol demands the DER units to stop supplying the microgrid [32].

The protection engineers zonalized the actual microgrid based on cable impedance and load requirement. Also the power system tools are used to deduce the relay settings.

The grid connected microgrid is prone to events like normal condition, resynchronization, and fault in feeder/utility grid (UG) /bus [33-34]. The most prominent fault in feeder/UG/ bus is due to overcurrent condition. Microgrids are subjected to frequent network reconfiguration that in turn causes variation in both fault current magnitude and direction. These are reasons why the conventional protection schemes are not suitable for microgrid. When the microgrid is operating in grid connected mode, the fault current is 20-50 times the anticipated current. In a IIDG based microgrid, the fault current is significantly less. At the fault location, it is only about $50 \%$ of its rated current. Usually, 1.1 to 1.2 times the rated DER current is provided to a fault by DER [35-36]. Other protection issues include underreach, sympathetic tripping, unsuccessful clearing of faults, fault current level variation and unintentional islanding [37].

Adaptive protection with appropriate communication protocols is a solution for protecting microgrid. This is costly but minimizes outage time and opportunity loss, but it involves high initial investment. Adaptive directional interlock is a scheme utilized in islanded microgrid wherein the tripping time maybe set at fixed value for all circuit breakers [38-39].

In this paper, an adaptive overcurrent protection system is employed on a reconfigurable microgrid. The CPS is capable of monitoring and protecting the microgrid. The CPS contains a LUT with information about normal and fault current of feeders in the network; optimized values of time multiplier settings and the time of operation of relay. With the assistance of the LUT, the CPS adaptively provides a suitable overcurrent relay coordination scheme for a fault in the microgrid. The hardware implementation is done with RS-232 communication standards and is validated successfully on a standard IEEE 21-bus microgrid network. The LUT assisted CPS may also result in minimum load centre disconnection for a fault at any feeder for a particular topology of the microgrid.

\section{Problem Formulation}

The overcurrent relay coordination is treated as an optimization problem [40-43]. The objective is to minimize time of operation of relays using (1). topj is calculated using (2). In (2), $\alpha$ is determined using (3). 


$$
\begin{aligned}
\operatorname{Min} \mathrm{z} & =\sum_{\mathrm{t}_{\mathrm{opj}}=\alpha(\mathrm{TMS})}^{\mathrm{n}} \mathrm{t}_{\mathrm{opj}} \\
\alpha & =\frac{\lambda}{(P S M)^{\gamma}-1}
\end{aligned}
$$

$\lambda$ and $\gamma$ are taken as 0.14 and 0.02 respectively, since all the relays in the microgrid network are assumed to have IDMT characteristics. The PSM is given by

$$
P S M=\frac{I_{f}}{C T \text { ratio }^{*} R S}
$$

\section{Constraints:}

Operating Time

$$
\mathrm{t}_{\text {opjmin }} \leq \mathrm{t}_{\text {opj }} \leq \mathrm{t}_{\text {opjmax }}
$$

$t_{\text {opjmin }}$ is dependent on the breaker operating time, coordination time interval of relays and communication delay, if any.

The industry practice $t_{\text {opjmax }}$ of relay is between 1 second to 3 seconds.

\section{Coordination Time Criteria}

CTI between relays should be maintained at all times. It is necessary that the difference between the operating times of adjacent relays must be greater than or equal to the CTI. It is assumed to be 0.2 for purpose of analysis.

$$
t_{\text {opjb }}-t_{\text {opj }} \geq C T I
$$

\section{Proposed Adaptive Protection of Microgrid}

The proposed adaptive protection system consists of two modules, each having a computer and a microcontroller ATmega2560 (Arduino Mega) as shown in Fig. 1. The computers are used to realize a GMFDS and CPS in a microgrid. The two systems are interfaced through Arduino A1 and A2. The steps involved in adaptive monitoring and protection of microgrid are as follows:

i) GMFDS simulates the microgrid test system. It continuously captures the status of microgrid (normal or fault condition) and then transmits this information as serial data to A1.

ii) A1 acts as analog to digital converter and it converts the serial data to parallel data. This data is transmitted to A2 where the parallel data is converted into serial data and transmitted to CPS.

iii) The information about the normal current, fault current, TMS and the instant of operation of the concerned relays for the possible topologies of the microgrid network are stored in the LUT of the CPS. Once a fault is diagnosed in the network, the CPS with the assistance of data in the LUT immediately determines the current configuration of the network. It identifies the exact location of the fault in the microgrid and issues the appropriate tripping sequence to the circuit breakers in the test system, which is simulated in GMFDS. iv) After clearing the fault, the CPS continues to monitor the $\overline{\mathrm{e}}^{-1}$ post fault network and provides suitable protection as and when required.

Adaptive overcurrent protection scheme is implemented for the balanced IEEE 21-bus microgrid test system illustrated in Fig. 2. The test system specification is as in Appendix 1. Due to reconfiguration, the topology of the microgrid network shown in Fig. 2 changes.

Among the possible topologies of the system, 10 different topologies indicated in Table 1 are considered for analysis. These different topologies are individually simulated using MATLAB/Simulink to obtain the normal and faulted feeder currents. These values aid in deciding the CT ratio for the individual feeders. For the 21-bus test system, the CT ratio are fixed as in Table 2.

Load flow analysis is done for the 21-bus microgrid test system with feeder 4 disconnected for specific loading conditions. This provides the current and voltage parameters under normal condition as shown in Table 3. For this topology, fault analysis is done for faults at different buses which are shown in Table 4. Likewise the normal and fault currents for the remaining configuration of the system are also obtained from load flow analysis and stored in LUT. The next step is to identify the TMS and $t_{\text {op }}$ values of relays using Dual Simplex Method for all possible topologies and fault locations.

\subsection{Determination of optimized TMS and top values using Dual Simplex algorithm}

The optimization problem is to minimize the relays operating time using the Dual Simplex algorithm. It is used for solving LPP. It is a more economical approach as it requires less number of iterations to converge. This method only solves maximization functions, so the minimization function should be converted to maximization function. Since the objective function in (1) is a minimization problem, the constraints should be less than or equal to type. Steps:

1) Form a matrix containing the linear programming problem (LPP) and constraints according to the given variables $(\mathrm{x} 1, \mathrm{x} 2 .$.$) .$

2) Take the transpose of the matrix and formulate the LPP as a function of new variables (y1, y2..).The number of constraints has thus been reduced.

3) Add the slack variables and solve the problem using simplex method for which we tabulate the new variables (y1, y2..), their coefficients, constraints and the LPP.

4) Perform iterations till the solution of the LPP is obtained.

5) Replace it in the LPP to obtain the value of the operating time of relay.

Using the algorithm, the TMS of the relays for the 10 different topologies for fault at 3 different locations for each 
INTERNATIONAL JOURNAL of SMART GRID, ijSmartGrid

O. V. G. Swathika and S. Hemamalini ,Vol. 2, No. 1, March, 2018

topology is computed as shown in Table 5. This eventually aids in computing the time of operation of relays. The data in
Table 4 and Table 5 are saved as records in a look up table in CPS.

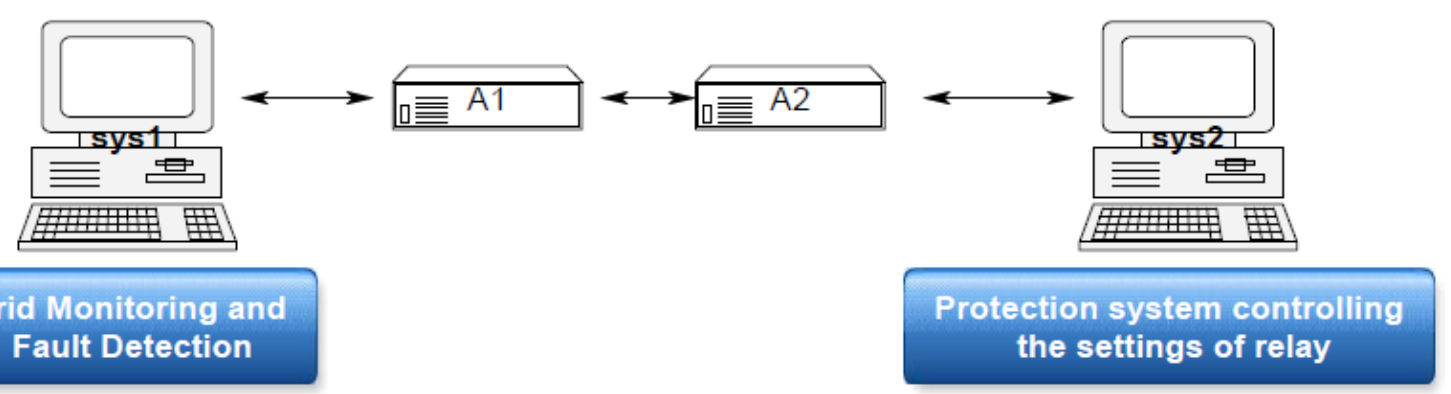

Fig. 1. Adaptive protection of microgrid

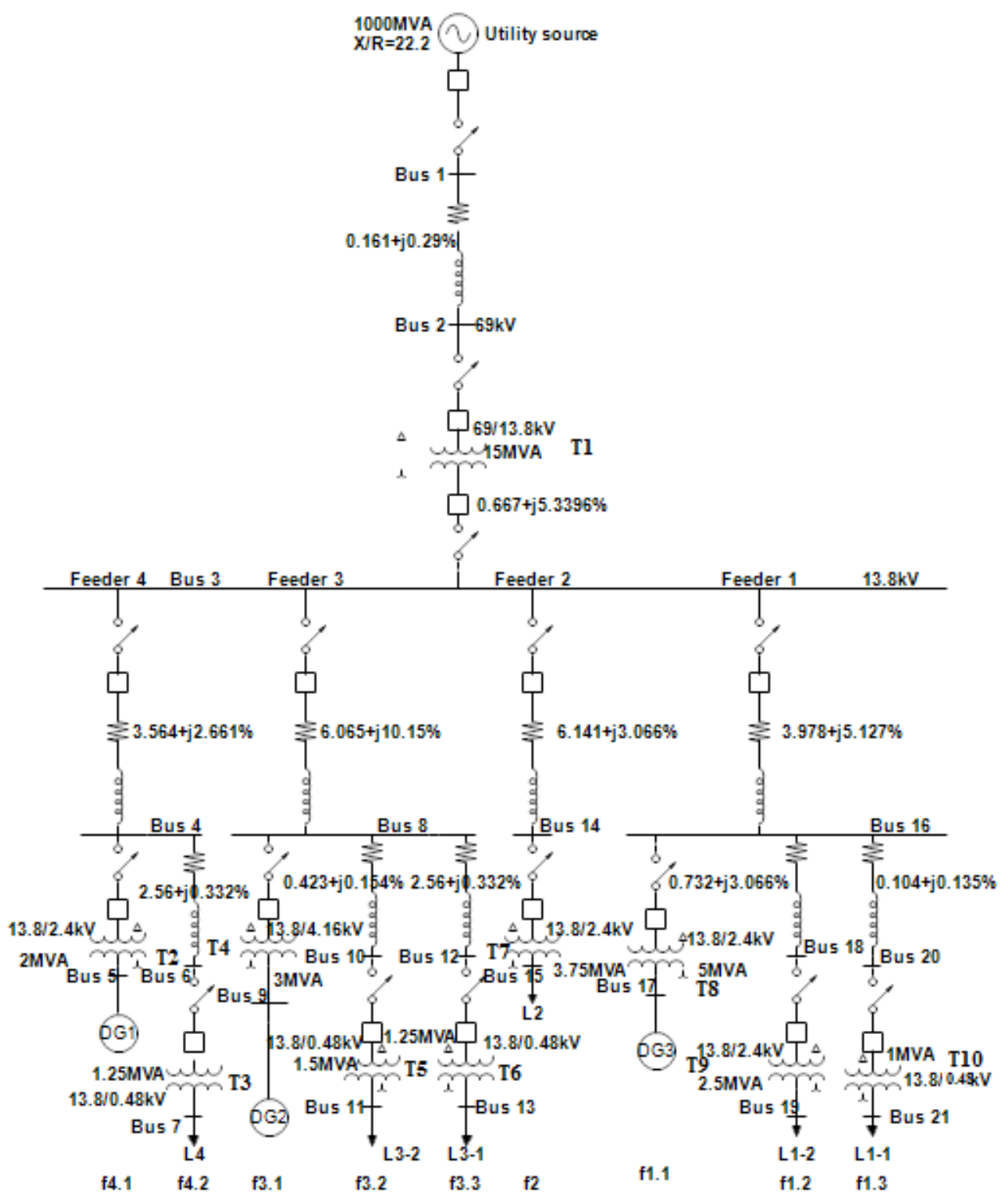

Fig. 2. IEEE 21-bus microgrid test system 
INTERNATIONAL JOURNAL of SMART GRID, ijSmartGrid

O. V. G. Swathika and S. Hemamalini ,Vol. 2, No. 1, March, 2018

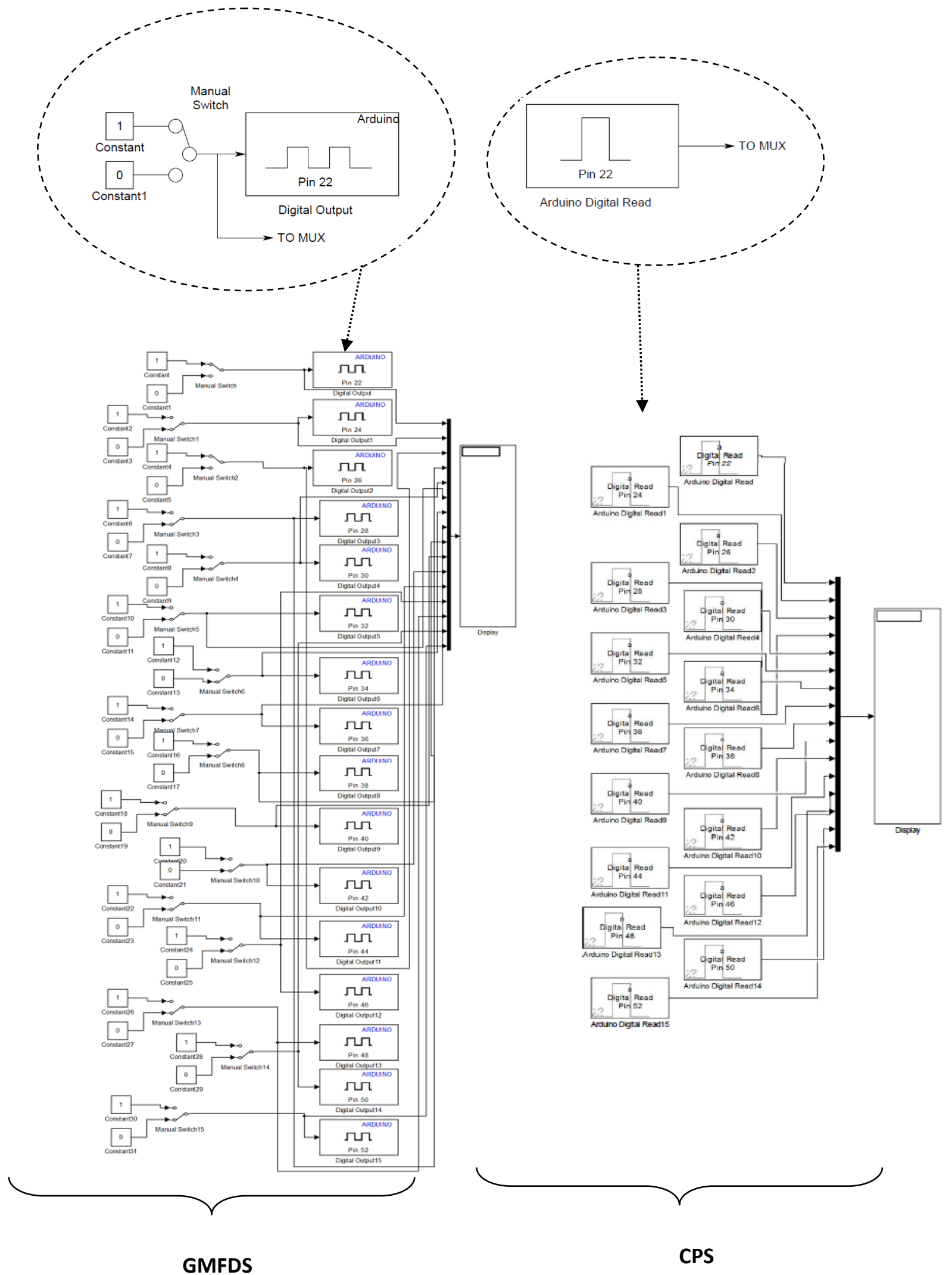

Fig. 3. Connectivity testing between GMFDS and CPS 
INTERNATIONAL JOURNAL of SMART GRID, ijSmartGrid

O. V. G. Swathika and S. Hemamalini ,Vol. 2, No. 1, March, 2018

Table 1. Reconfigured Microgrid Topologies

\begin{tabular}{|c|c|}
\hline DISCONNECTED FEEDERS & CONNECTED FEEDERS \\
\hline None & $\mathrm{f} 1, \mathrm{f} 2, \mathrm{f} 3, \mathrm{f} 4$ \\
\hline $\mathrm{f} 1$ & $\mathrm{f} 2, \mathrm{f} 3, \mathrm{f} 4$ \\
\hline $\mathrm{f} 2$ & $\mathrm{f} 1, \mathrm{f} 3, \mathrm{f} 4$ \\
\hline $\mathrm{f} 3$ & $\mathrm{f} 1, \mathrm{f} 2, \mathrm{f} 4$ \\
\hline $\mathrm{f} 4$ & $\mathrm{f} 1, \mathrm{f} 2, \mathrm{f} 3$ \\
\hline $\mathrm{f} 1, \mathrm{f} 2$ & $\mathrm{f} 3, \mathrm{f} 4$ \\
\hline $\mathrm{f} 1, \mathrm{f} 4$ & $\mathrm{f} 2, \mathrm{f} 3$ \\
\hline $\mathrm{f} 2, \mathrm{f} 3$ & $\mathrm{f} 1, \mathrm{f} 4$ \\
\hline $\mathrm{f} 2, \mathrm{f} 4$ & $\mathrm{f} 1, \mathrm{f} 3$ \\
\hline $\mathrm{f} 3, \mathrm{f} 4$ & $\mathrm{f} 1, \mathrm{f} 2$ \\
\hline
\end{tabular}

Table 2. CT ratio Assigned to Individual Feeders

\begin{tabular}{|c|c|}
\hline RELAY AT & CT RATIO \\
\hline $\begin{array}{c}\text { BEUS 1,2 } \\
\text { DG 2 }\end{array}$ & $5: 1$ \\
\hline BUS 3 & $30: 1$ \\
\hline $\begin{array}{c}\text { FEEDER 1 } \\
\text { DG 3 }\end{array}$ & $20: 1$ \\
\hline $\begin{array}{c}\text { FEEDER 2 } \\
\text { BUS 14,18 }\end{array}$ & $50: 1$ \\
\hline FEEDER 4 \\
DG 1
\end{tabular}


Table 3. Current and voltage parameters at outgoing feeders with feeder 4 disconnected

\begin{tabular}{|l|l|l|l|l|}
\hline Feeder & $\begin{array}{l}\text { Primary } \\
\text { voltage } \\
\left(\mathbf{V}_{\mathbf{p}}\right) \text { in } \mathbf{k V}\end{array}$ & $\begin{array}{l}\text { Primary current } \\
\left(\mathbf{I}_{\mathbf{p}}\right) \text { in } \mathbf{k A}\end{array}$ & $\begin{array}{l}\text { Secondary } \\
\text { voltage }\left(\mathbf{V}_{\mathbf{s}}\right) \\
\text { in } \mathbf{~} \mathbf{V}\end{array}$ & $\begin{array}{l}\text { Secondary } \\
\text { current }\left(\mathbf{I}_{\mathbf{s}}\right) \\
\text { in } \mathbf{k A}\end{array}$ \\
\hline f1.1 & 13.758 & 0.0696 & 2.4008 & 0.398672 \\
\hline f1.2 & 13.758 & 0.1037 & 2.3776 & 0.600247 \\
\hline f1.3 & 13.758 & 0.0041 & 0.4782 & 0.11896 \\
\hline f2 & 13.758 & 0.1556 & 2.3776 & 0.9003 \\
\hline f3.1 & 13.758 & 0.0417 & 4.16137 & 0.138 \\
\hline f3.2 & 13.758 & 0.00165 & 0.478223 & 0.04746 \\
\hline f3.3 & 13.758 & 0.051865 & 0.475523 & 1.50062 \\
\hline
\end{tabular}

\section{Results and Discussion}

The look up table created in CPS contains information on: normal current, fault current, TMS and $t_{\mathrm{op}}$ of relays for all the topologies of the network as explained in Section 3. Initially the connectivity testing between the GMFDS and CPS Modules are established so as to enable the adaptive monitoring and protection of microgrid test system. The adaptive protection system ensures that the microgrid is continuously monitored and in the event of fault, the appropriate overcurrent relay coordination scheme is employed on the network. This scheme may trigger minimum load centre disconnection.

\subsection{Connectivity Testing between GMFDS and CPS}

The connectivity between GMFDS and CPS is established through Arduino boards A1 and A2 as shown in Fig.1. Fig. 3 shows the Simulink models that are executed in GMFDS and CPS to check the connectivity that exists between them. Both the Simulink models use the same pin numbers for the Arduino I/O blocks to test the parallel communication between the two systems. To test the connectivity between GMFDS and CPS modules, the position of all the switches in GMFDS is changed one by one. If the position change immediately reflects in CPS, then it confirms that an intact communication exists between the two systems.

In the Simulink model in GMFDS, the switches are connected to the Digital Output blocks. Each digital output block synchronously outputs the latest set of data to the MUX, display unit, A1 and A2. From A2, the digital input is captured by CPS using Arduino read blocks. The output of all the Arduino read blocks are fed to a MUX and then onto a display unit. Thus at any instant, whenever a switch changes position in the GMFDS, its corresponding status is captured in CPS. If the correct status of the switch is displayed in CPS then it implies that the connectivity is established between GMFDS and CPS.

\subsection{Hardware prototype of adaptive OCR coordination}

The hardware prototype of the GMFDS-CPS interfacing for adaptive protection of microgrid is shown in Fig. 4. After testing the connectivity between GMFDS and CPS, the Simulink model of the 21-bus test system is simulated in the GMFDS. Each circuit breaker in the test system is individually monitored and controlled by a FSS. In CPS an initialization program is first executed to establish the port connectivity between GMFDS and CPS. The MATLAB program for adaptive overcurrent protection is executed in CPS. This program performs the following functionalities:

- Identifies the configuration of the network.

- Grid monitoring.

- Compares the monitored current parameters with the data in the LUT.

- Identifies the actual location of fault in the network.

- CPS issues trip commands to appropriate CBs through FSS in GMFDS.

Let a fault be initiated in the specific feeder by positioning SW2 to '1'. This information is sent to S1 port of SW3 switch and through Out19 as input to FCB. The FCB is a 16 input OR gate, where each input is the fault initiation status from 16 feeders of the test system. Since Out19 carries logic ' 1 ', the output of FCB becomes ' 1 ', which is in turn fed to In1 port of the FSS. The In1 port data is eventually passed to $\mathrm{CS}$. As $\mathrm{CS}=$ ' 1 ', the data in $\mathrm{S} 1$ is the output of SW3 and is sent through the Arduino Digital Write Pin 22 to CPS. This informs the CPS of a fault occurence in the specific feeder of the test system. 
Table 4. Fault current on all feeders (with feeder 4 disconnected)

\begin{tabular}{|c|c|c|c|c|c|c|c|c|c|c|c|c|c|c|c|}
\hline \multirow{2}{*}{$\begin{array}{c}\text { FAULT } \\
\text { LOCATIO } \\
\text { N }\end{array}$} & \multirow{2}{*}{$\begin{array}{l}\text { FAUL } \\
\quad \text { T } \\
\text { TYPE }\end{array}$} & \multicolumn{2}{|c|}{ F1.1 } & \multicolumn{2}{|c|}{ F1.2 } & \multicolumn{2}{|c|}{ F1.3 } & \multicolumn{2}{|c|}{ F2 } & \multicolumn{2}{|c|}{ F3.1 } & \multicolumn{2}{|c|}{ F3.2 } & \multicolumn{2}{|c|}{ F3.3 } \\
\hline & & $\mathrm{P}$ & $S$ & $\mathrm{P}$ & $S$ & $\mathrm{P}$ & S & $\mathrm{P}$ & $S$ & $\mathrm{P}$ & S & $\mathrm{P}$ & S & $\mathrm{P}$ & S \\
\hline \multirow{2}{*}{ Bus 21} & $3 \emptyset-G$ & 261.5 & 225 & 1.895 & 159.7 & \multicolumn{2}{|c|}{$I_{F}=9800$} & 781.2 & 788.7 & 63.25 & 55.92 & 1567 & 1583 & 1306 & 1319 \\
\hline & $3 \varnothing$ & 261.5 & 225 & 1.895 & 159.7 & \multicolumn{2}{|c|}{$I_{F}=6000$} & 781.2 & 788.7 & 63.25 & 55.92 & 1567 & 1583 & 1306 & 1319 \\
\hline & $3 \emptyset-G$ & 261.3 & 259.9 & \multicolumn{2}{|c|}{$I_{F}=9500$} & 121.7 & 28.7 & 780.7 & 780.8 & 63.26 & 62.99 & 1567 & 1567 & 1306 & 1306 \\
\hline & $3 \varnothing$ & 261.3 & 259.9 & \multicolumn{2}{|c|}{$I_{F}=5500$} & 121.7 & 28.7 & 780.7 & 780.8 & 63.26 & 62.99 & 1567 & 1567 & 1306 & 1306 \\
\hline Bus 17 & $3 \varnothing-G$ & \multicolumn{2}{|c|}{$I_{F}=9000$} & 2.169 & 7.49 & 63.65 & 14.9 & 781 & 781 & 63.4 & 63.13 & 1567 & 1567 & 1306 & 1306 \\
\hline & $3 \varnothing$ & \multicolumn{2}{|c|}{$I_{F}=6000$} & 2.169 & 7.49 & 63.65 & 14.9 & 781 & 781 & 63.4 & 63.13 & 1567 & 1567 & 1306 & 1306 \\
\hline Bus 15 & $3 \varnothing-G$ & 198.1 & 187.5 & 221.7 & 245 & 443.5 & 489.4 & \multicolumn{2}{|c|}{$I_{F}=12000$} & 341.4 & 322.2 & 852.5 & 728.5 & 562 & 607.2 \\
\hline & $3 \varnothing$ & 198.1 & 187.5 & 221.7 & 245 & 443.5 & 489.4 & \multicolumn{2}{|c|}{$I_{F}=8000$} & 341.4 & 322.2 & 852.5 & 728.5 & 562 & 607.2 \\
\hline Bus 13 & $3 \varnothing-G$ & 246.5 & 92.33 & 449.1 & 438.3 & 898.5 & 877 & 592.5 & 655.6 & 450.8 & 156.9 & 1146 & 1284 & \multicolumn{2}{|c|}{$I_{F}=10000$} \\
\hline & $3 \varnothing$ & 246.5 & 92.33 & 449.1 & 438.3 & 898.5 & 877 & 592.5 & 655.6 & 450.8 & 156.9 & 1146 & 1284 & \multicolumn{2}{|c|}{$I_{F}=8000$} \\
\hline Bus 11 & $3 \emptyset-G$ & 238.4 & 91.22 & 66.98 & 440.3 & 134 & 881 & 92.14 & 658.6 & 435.4 & 154.8 & \multicolumn{2}{|c|}{$I_{F}=12000$} & 78.98 & 1076 \\
\hline & $3 \varnothing$ & 238.4 & 91.22 & 66.98 & 440.3 & 134 & 881 & 92.14 & 658.6 & 435.4 & 154.8 & \multicolumn{2}{|c|}{$I_{F}=5000$} & 78.98 & 1076 \\
\hline Bus 9 & $3 \emptyset-G$ & 248 & 243.1 & 38.61 & 53.15 & 77.26 & 106.3 & 48.96 & 71.1 & \multicolumn{2}{|c|}{$I_{F}=10000$} & 1301 & 506.3 & 16 & 42.21 \\
\hline & $3 \varnothing$ & 248 & 243.1 & 38.61 & 53.15 & 77.26 & 106.3 & 48.96 & 71.1 & \multicolumn{2}{|c|}{$I_{F}=9000$} & 1301 & 506.3 & 16 & 42.21 \\
\hline
\end{tabular}


Table 5. TMS and $t_{o p}$ values using Dual Simplex Algorithm

\begin{tabular}{|c|c|c|c|c|c|c|c|c|c|c|c|c|c|c|c|c|c|c|c|c|c|c|c|c|c|}
\hline \multirow{3}{*}{\multicolumn{2}{|c|}{ CASE }} & \multicolumn{24}{|c|}{ CIRCUIT BREAKER FOR } \\
\hline & & \multicolumn{3}{|c|}{ BUS6 } & \multicolumn{3}{|c|}{ DG2 } & \multicolumn{3}{|c|}{ BUS10 } & \multicolumn{3}{|c|}{ BUS12 } & \multicolumn{3}{|c|}{ BUS14 } & \multicolumn{3}{|c|}{ DG3 } & \multicolumn{3}{|c|}{ BUS18 } & \multicolumn{3}{|c|}{ BUS20 } \\
\hline & & a & TMS & $t_{\text {op }}$ & a & TMS & $t_{\text {op }}$ & a & TMS & $t_{\text {op }}$ & a & TMS & $t_{o p}$ & a & TMS & $t_{\text {op }}$ & a & TMS & $t_{\text {op }}$ & a & TMS & $t_{\text {op }}$ & a & TMS & $t_{\text {op }}$ \\
\hline \multirow{3}{*}{ NORMAL } & FAULT AT BUS7 & 4 & 0.05 & 0.2 & & & & & & & & & & & & & & & & & & & & & \\
\hline & FAULT AT BUS13 & & & & & & & & & & 4.18 & 0.05 & & & & & & & & & & & & & \\
\hline & FAULT AT BUS21 & & & & & & & & & & & & & & & & & & & & & & 9.7 & 0.02 & 0.19976 \\
\hline \multirow{3}{*}{$\begin{array}{c}\text { FEEDER1 } \\
\text { DISCONNECTED }\end{array}$} & FAULT AT BUS7 & 4.2 & 0.05 & 0.2 & & & & & & & & & & & & & & & & & & & & & \\
\hline & FAULT AT BUS13 & & & & & & & & & & 4.18 & 0.05 & & & & & & & & & & & & & \\
\hline & FAULT AT BUS15 & & & & & & & & & & & & & 6.1 & 0.03 & 0.2 & & & & & & & & & \\
\hline \multirow{3}{*}{$\begin{array}{c}\text { FEEDER2 } \\
\text { DISCONNECTED }\end{array}$} & FAULT AT BUS7 & 4.2 & 0.05 & 0.2 & & & & & & & & & & & & & & & & & & & & & \\
\hline & FAULT AT BUS13 & & & & & & & & & & 4.18 & 0.05 & 0.2 & & & & & & & & & & & & \\
\hline & FAULT AT BUS21 & & & & & & & & & & & & & & & & & & & & & & 9.6 & 0.02 & 0.2 \\
\hline \multirow{3}{*}{$\begin{array}{c}\text { FEEDER3 } \\
\text { DISCONNECTED }\end{array}$} & FAULT AT BUS7 & 4.2 & 0.05 & 0.2 & & & & & & & & & & & & & & & & & & & & & \\
\hline & FAULT AT BUS15 & & & & & & & & & & & & & 6.1 & 0.03 & 0.2 & & & & & & & & & \\
\hline & FAULT AT BUS21 & & & & & & & & & & & & & & & & & & & & & & 9.6 & 0.02 & 0.2 \\
\hline \multirow{3}{*}{$\begin{array}{c}\text { FEEDER4 } \\
\text { DISCONNECTED }\end{array}$} & FAULT AT BUS13 & & & & & & & & & & 4.18 & 0.05 & 0.2 & & & & & & & & & & & & \\
\hline & FAULT AT BUS15 & & & & & & & & & & & & & 6.1 & 0.03 & 0.2 & & & & & & & & & \\
\hline & FAULT AT BUS21 & & & & & & & & & & & & & & & & & & & & & & 9.6 & 0.02 & 0.2 \\
\hline \multirow{3}{*}{$\begin{array}{c}\text { FEEDER1\&2 } \\
\text { DISCONNECTED }\end{array}$} & FAULT AT BUS7 & 4.2 & 0.05 & 0.2 & & & & & & & & & & & & & & & & & & & & & \\
\hline & FAULT AT BUS11 & & & & & & & 14 & 0.01 & 0.2 & & & & & & & & & & & & & & & \\
\hline & FAULT AT BUS13 & & & & & & & & & & 4.18 & 0.05 & 0.2 & & & & & & & & & & & & \\
\hline \multirow{3}{*}{$\begin{array}{c}\text { FEEDER1\&4 } \\
\text { DISCONNECTED }\end{array}$} & FAULT AT BUS11 & & & & & & & 14 & 0.01 & 0.2 & & & & & & & & & & & & & & & \\
\hline & FAULT AT BUS13 & & & & & & & & & & 4.18 & 0.05 & 0.2 & & & & & & & & & & & & \\
\hline & FAULT AT BUS15 & & & & & & & & & & & & & 6.1 & 0.03 & 0.2 & & & & & & & & & \\
\hline \multirow{3}{*}{$\begin{array}{c}\text { FEEDER2\&3 } \\
\text { DISCONNECTED }\end{array}$} & FAULT AT BUS7 & 4.2 & 0.05 & 0.2 & & & & & & & & & & & & & & & & & & & & & \\
\hline & FAULT AT BUS19 & & & & & & & & & & & & & & & & & & & 9.5 & 0.02 & 0.2 & & & \\
\hline & FAULT AT BUS21 & & & & & & & & & & & & & & & & & & & & & & 9.6 & 0.02 & 0.2 \\
\hline \multirow{3}{*}{$\begin{array}{c}\text { FEEDER2\&4 } \\
\text { DISCONNECTED }\end{array}$} & FAULT AT BUS11 & & & & & & & 14.1 & 0.01 & 0.2 & & & & & & & & & & & & & & & \\
\hline & FAULT AT BUS13 & & & & & & & & & & 4.2 & 0.05 & 0.2 & & & & & & & & & & & & \\
\hline & FAULT AT BUS21 & & & & & & & & & & & & & & & & & & & & & & 9.6 & 0.02 & 0.2 \\
\hline \multirow{3}{*}{$\begin{array}{c}\text { FEEDER3\&4 } \\
\text { DISCONNECTED }\end{array}$} & FAULT AT BUS15 & & & & & & & & & & & & & 6.1 & 0.03 & 0.2 & & & & & & & & & \\
\hline & FAULT AT BUS19 & & & & & & & & & & & & & & & & & & & 9.5 & 0.02 & 0.2 & & & \\
\hline & FAULT AT BUS21 & & & & & & & & & & & & & & & & & & & & & & 9.6 & 0.02 & 0.2 \\
\hline
\end{tabular}


Table 6. TMS and $\mathrm{t}_{\mathrm{op}}$ (contd.)

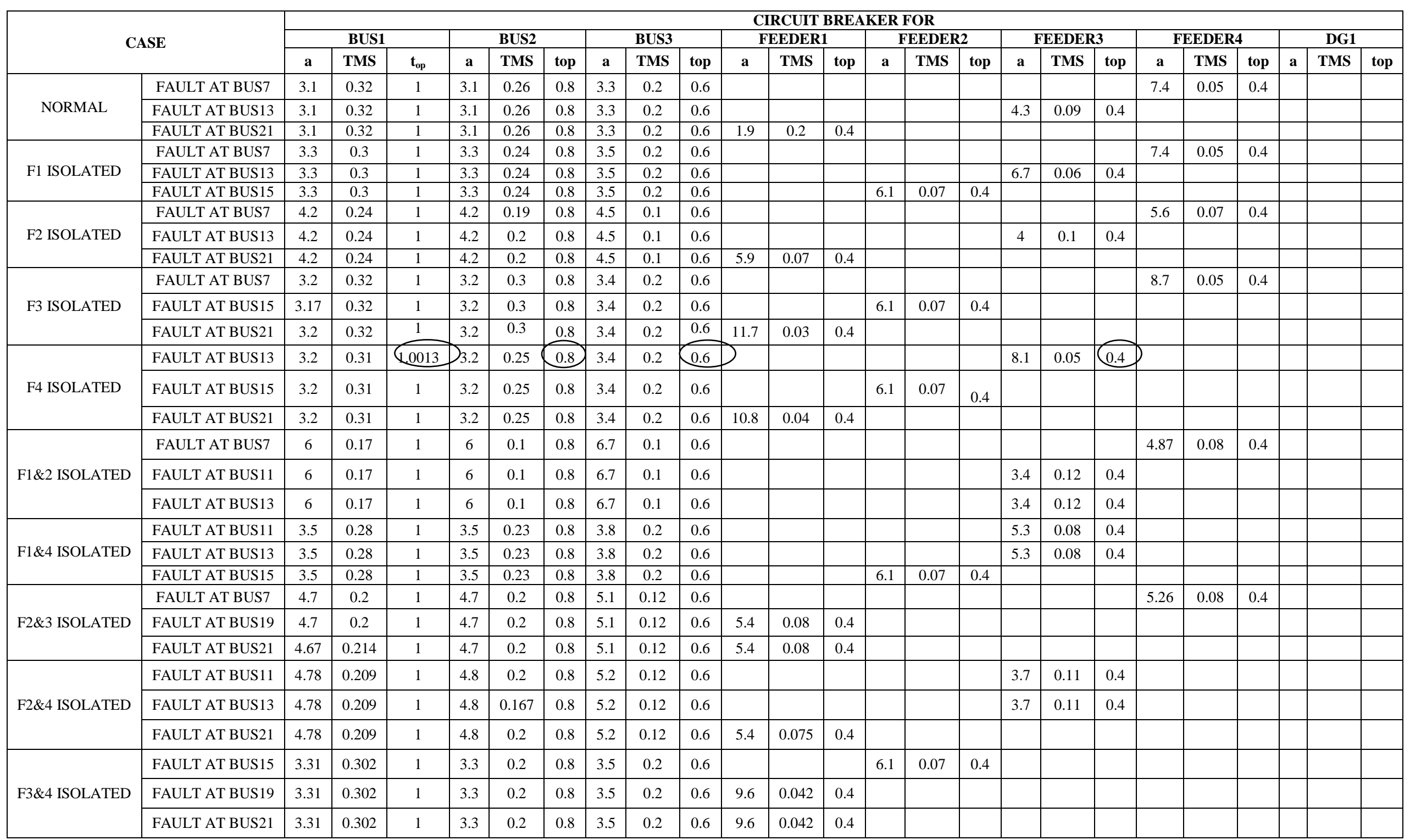


The CPS with the assistance of LUT issues appropriate trip signals for the concerned breakers in the specific feeder based on the optimized time of operation values of relays. This trip signal is captured through Arduino Digital Read pin 23 and fed as an input to the 2input AND gate. Let $\mathrm{SW} 1=$ ' 1 ' be the other input of AND gate and hence the output of AND gate is logic ' 1 ', that is transferred to Out18, connected to the external logic control of $\mathrm{CB}$ that eventually trips. Once the breaker is tripped, this information is passed to Arduino Digital Write pin 22 and then on to CPS through S2 data port of SW3. This informs the CPS that the trip signals are issued to the circuit breaker.
To validate the adaptive overcurrent relay coordination protection system on the 21-bus microgrid system, a fault is initiated at bus 13 with feeder 4 disconnected. The breakers involved in fault clearance from downstream to upstream are circled in Table 4 . The optimized operating time of these breakers are $0.1998 \mathrm{~s}$, $0.39996 \mathrm{~s}, 0.59856 \mathrm{~s}, 0.80104 \mathrm{~s}, 1.0013 \mathrm{~s}$ respectively as indicated in Fig. 6. The proposed scheme is validated since the breaker operation time as indicated in Fig. 6 matches exactly with the time of operation programmed in the LUT in CPS as circled in Table 4. The hardware prototype is also tested and validated for all reconfigured topologies of the 21-bus network. The proposed adaptive protection scheme may be employed on any real-time grid by altering the LUT accordingly.

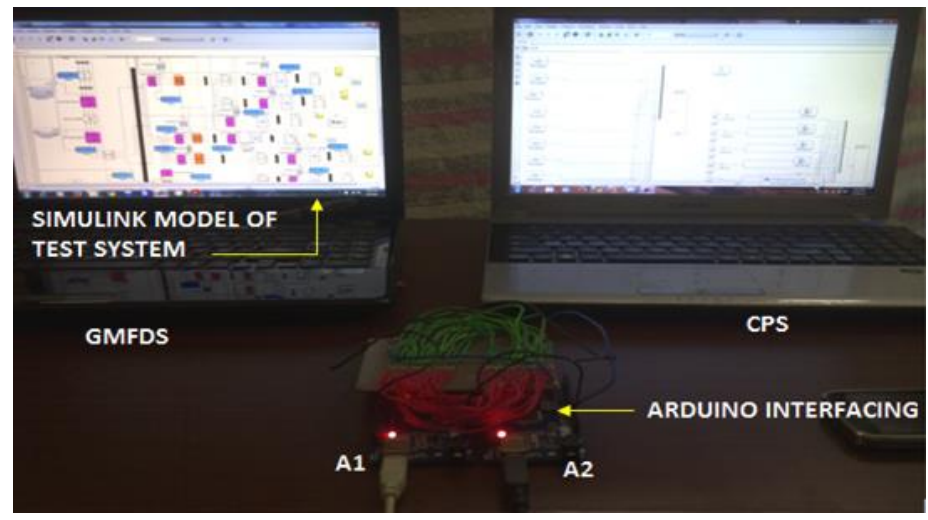

Fig. 4. Hardware prototype of GMFDS-CPS interfacing for adaptive protection of microgrid

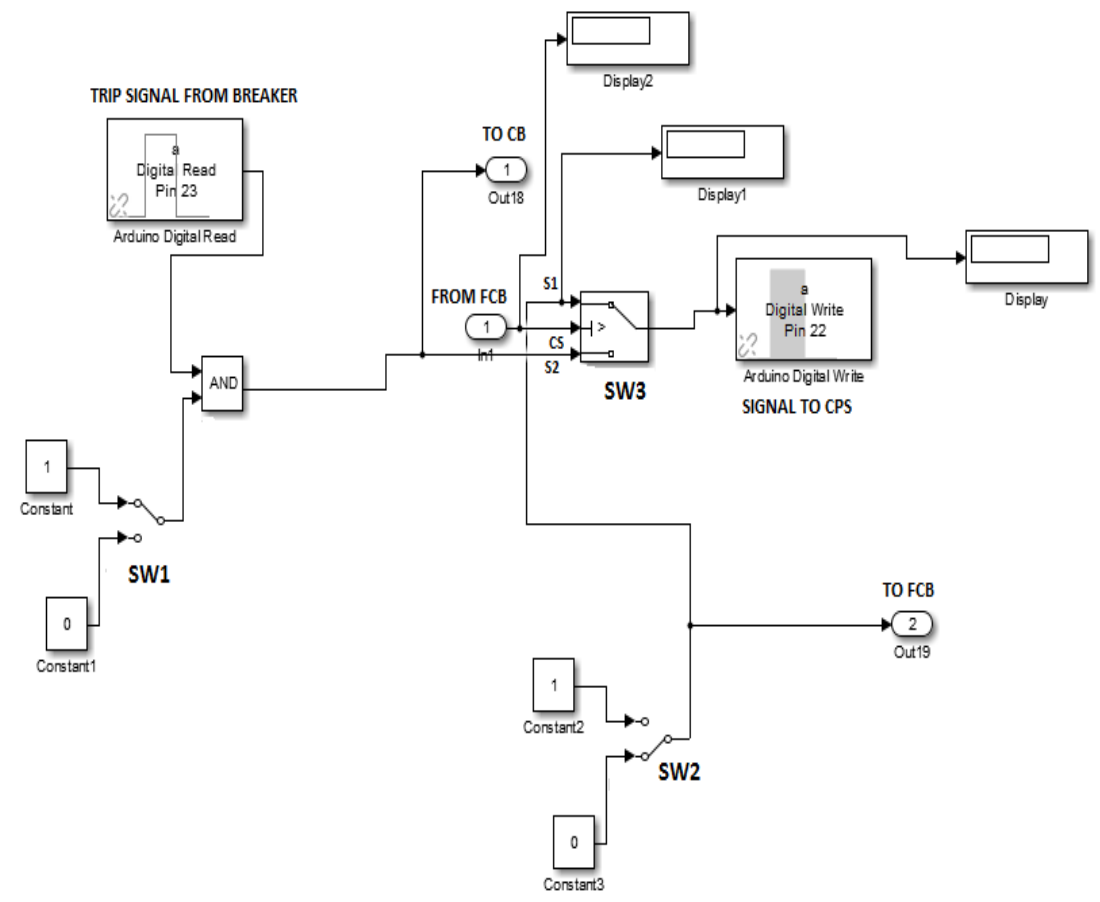

Fig. 5. Fault switching subsystem 


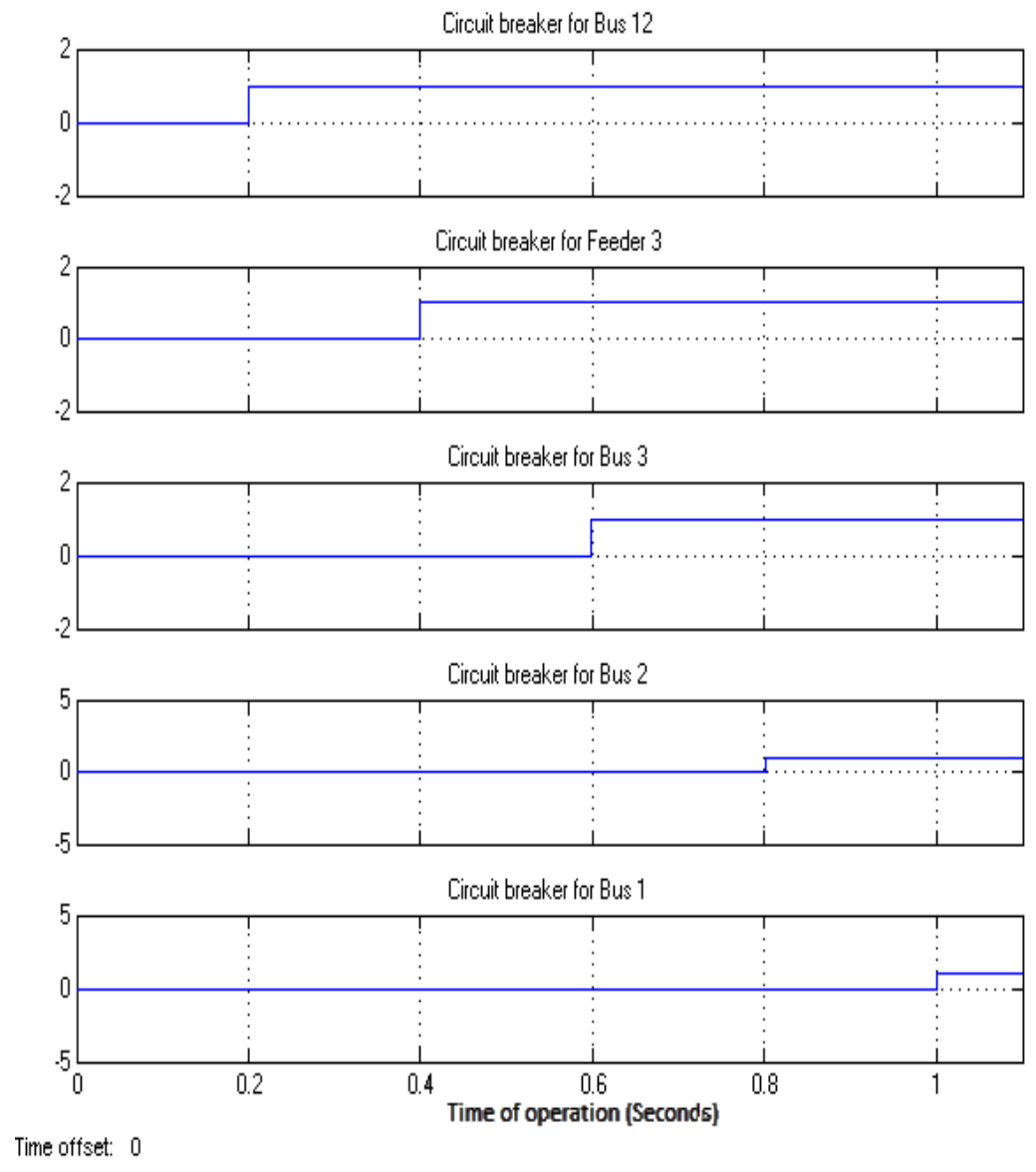

Fig. 6. OCR coordination when fault is introduced at Bus 13 in feeder 4 disconnected topology

\section{Conclusion}

An intelligent and adaptive overcurrent protection system is developed for a microgrid system with monitoring and protection control features. The reconfigurable 21-bus microgrid network is simulated in the GMFDS. The GMFDS is in turn interfaced through Arduino ATMega 2560 to the CPS that contains a look up table (LUT) that maintains information of normal and fault current in all feeders for all possible topologies of the microgrid system. Dual Simplex algorithm is used in identifying the optimized values for TMS and $t_{\text {op }}$ of relays for faults at any location in any reconfigured system. This information is also saved in LUT. With the assistance of LUT, the CPS identifies the fault location and provides suitable overcurrent relay coordination for the test system. In the event of fault occurrence, the LUT may trigger only minimum load centre disconnection. The hardware prototype of the adaptive overcurrent relay coordination is realized, tested and validated on the reconfigurable 21-bus microgrid network.

\footnotetext{
Appendix 1:

Parameters of IEEE 21-bus microgrid network:

Base voltage: $69 \mathrm{kV}$; Base MVA: 1000MVA;

Frequency: $50 \mathrm{~Hz}$; X/R ratio: 22.2

Power factor: 0.9992

Feeder1: f1.1 13.8kV/2.4kV; f1.2 $13.8 \mathrm{kV} / 2.4 \mathrm{kV}$;

f1.3 $13.8 \mathrm{kV} / 0.48 \mathrm{kV}$
}

Feeder2: f2 $13.8 \mathrm{kV} / 2.4 \mathrm{kV}$

Feeder3: f3.1 13.8 kV /0.48 kV; f3.2 13.8 kV /0.48

$\mathrm{kV} ;$ f3.3 $13.8 \mathrm{kV} / 0.48 \mathrm{kV}$

Feeder4: f4.1 13.8 kV /2.4 kV; f4.2 13.8 kV /0.48 kV DG1: 2.4kV, 2MVA; DG2: 4.16kV, 3MVA; DG3:

$2.4 \mathrm{kV}, 2.5 \mathrm{MVA}$;

Loads: L1-1: 0.48kV, 1MVA; L1-2: 2.4kV, 2.5MVA;

L2: $2.4 \mathrm{kV}, 3.75 \mathrm{MVA}$;

L3-1 0.48kV, 1.25MVA; L3-2 0.48kV, 1.5MVA; L4

$0.48 \mathrm{kV}, 1.25 \mathrm{MVA}$;

Transformer configuration: $\Delta$-Y (ideal mode)

T1: 69/13.8kV, 15MVA; T2 13.8/2.4kV, 2MVA; T3

$13.8 / 0.48 \mathrm{kV}, 1.25 \mathrm{MVA}$

T4: 13.8/0.48kV, 3MVA; T5 13.8/0.48kV, 1.5MVA;

T6 13.8/0.48kV, 1.25MVA

T7: 13.8/2.4kV, 3.75MVA; T8 13.8/2.4kV, 5MVA;

T9 $13.8 / 2.48 \mathrm{kV}, 2.5 \mathrm{MVA}$

T10 13.8/2.4kV, 1MVA

\section{References}

[1] Swathika, O.G. and Hemamalini, S., Prims Aided Dijkstra Algorithm for Adaptive Protection in Microgrids. IEEE Journal of Emerging and Selected Topics in Power Electronics, 4(4), pp.1279-1286.

[2] Swathika, O.G. and Hemamalini, S., "Review on Microgrid and its Protection Strategies." International 
Journal of Renewable Energy Research (IJRER) 6.4 (2016): 1574-1587.

[3] Swathika, O. V., et al. "Hybrid Prims-Johnson's Algorithm for Shortest Path Identification in Reconfigurable Microgrid." Advanced Science Letters 22.10 (2016): 29222926.

[4] Swathika, O. V., et al. "Shortest Path Identification in Reconfigurable Microgrid Using Hybrid Bellman FordDijkstra's Algorithm." Advanced Science Letters 22.10 (2016): 2932-2935.

[5] Taha Selim Ustun, Cagil Ozansoy and Aladin Zayegh, "Recent developments in microgrids and example cases around the world-A review," Renewable and Sustainable Energy Reviews: Elsevier, Vol. 15, pp. 4030-4041, 2011.

[6] Qian Ai, Xiaohong Wang and Xing He, "The impact of large-scale distributed generation on power grid and microgrids," Renewable Energy: Elsevier, Vol. 62, pp. 417-423, 2011.

[7] Prasenjit Basak, Chowdhury, S., Haldernee Dey, S., and Chowdhury, S.P., "A literature review on integration of distributed energy resources in the perspective of control, protection and stability of microgrid," Renewable and Sustainable Energy Reviews: Elsevier, Vol. 16, pp. 55455556, 2012.

[8] Taha Selim, Cagil Ozansoy, Aladin Zayegh, "Modelling of a Centralized Microgrid Protection System and Distributed Energy Resources According to IEC 61850-7-420," IEEE Transactions on Power Systems, vol.27, no.3, pp. 15601567, 2012.

[9] Javadian, S.A.M, Haghifam, M.R, Bathaee, S.M.T, and Fotuhi Firoozabad, M., "Adaptive centralized protection scheme for distribution systems with DG using risk analysis for protective devices placement," Electrical Power and Energy Systems, vol. 44, pp. 337-345, 2013.

[10] Taha Selim Ustun, Cagil Ozansoy and Ustun, A. "Fault current coefficient and time delay assignment for microgrid protection system with central protection unit," IEEE Transaction on Power System, vol. 28, no. 2, pp. 598-606, 2013.

[11] Oudalov, A., and Fidigatti, Adaptive Network Protection in Microgrids. [Online]. Available: http://www.microgrids.eu/documents/519.pdf

[12] Swathika, O.V., Indranil Bose, Bhaskar Roy, Suhit Kodgule and Hemamalini, S. "Optimization Techniques Based Adaptive Overcurrent Protection in Microgrids," Journal of Electrical Systems Special Issue 3, vol. 10, pp. 76-80, 2016.

[13] Javadian, S., Haghifam, M. R., and Rezaei, N. "A fault location and protection scheme for distribution systems in presence of dg using MLP neural networks," Proceeding IEEE Power Energy Society General Meeting Conference, pp. 1-8, 2009.

[14] Zayandehroodi, H., Mohamed, A., Shareef, H. and Farhoodnea, M. "A novel neural network and backtracking based protection coordination scheme for distribution system with distributed generation," International Journal Electrical Power Energy Systems, vol. 43, no. 1, pp. 868879, 2012.

[15] Swathika, O.G., Karthikeyan, K. and Hemamalini, S. "Multiple DG Synchronization and De-synchronization in a Microgrid Using PLC," Advanced Computing and Communication Technologies, Springer, pp. 565-572, 2016.

[16] Swathika, O.G. and Hemamalini, S. Communication Assisted Overcurrent Protection of Microgrid. IEEE Computational Intelligence and Communication Networks (CICN), 2015 International Conference, pp. 1472-1475, 2015.

[17] Hannu Laaksonen, Dmitry Ishchenko and Alexandre Oudalov, "Adaptive Protection and Microgrid Control Design for Hailuoto Island," IEEE Transactions on Smart Grid, Vol.5, No. 3, May 2014.

[18] Wen Lu, Yangdong Zhao, Weixing Li and Hongwei Du, "Design and application of microgrid operation control system based on IEC 61850," Springer: Journal of Mod. Power Syst. Clean Energy, Vol.2, No. 3, pp. 256-63, May 2014.

[19] Liang Che, Mohammad Khodayar, E., and Mohammad Shahidehpour, "Adaptive Protection System for Microgrids," IEEE Electrification Magazine, March 2014.

[20] Sohrab Mirsaeidi, Dalila MatSaid, Mohd.Wazir Mustafa, Mohd. Hafiz Habibuddin, Kimia Ghaffari, "Progress and problems in micro-grid protection schemes," Renewable and Sustainable Energy Reviews: Elsevier, Vol. 37, pp. 834-839, 2014.

[21] A. Oudalov and A. Fidgatti, "Adaptive network protection in microgrids", International Journal of Distributed Energy Resources, vol. 5, no.3, pp.201-226, 2009.

[22] Sekar Kannuppaiyan and Vivekanandan Chenniappan, "Numerical Inverse Definite Minimum Time Overcurrent Relay for Microgrid Power System Protection", IEEJ Transactions on Electrical and Electronic Engineering, vol. 10, no. 1, pp.50-54, 2015.

[23] O.V. Gnana Swathika and S. Hemamalini, "Adaptive and Intelligent Controller for Protection in Radial Distribution System", Springer Advanced Computer and Communication Engineering Technology, 362, pp. 195209, 2016.

[24] P. Prashant Bedekar and R. Sudhir Bhide, "Optimal coordination of overcurrent relay timing using continuous genetic algorithm", Elsevier Science Direct Expert System with Applications, vol. 38, pp. 11286-11292, 2011.

[25] Manohar Singh, B.K. Panigrahi and A.R. Abhyankar, "Optimal coordination of directional overcurrent relays using Teaching Learning-Based Optimization Algorithm (TLBO)", Electric Power and Energy Systems, vol. 50, pp. 33-41, 2013.

[26] Manoj Thakur and Anand Kumar, "Optimal coordination of directional overcurrent relays using a modified real coded genetic algorithm: A comparative study", Electric Power and Energy Systems, vol. 82, pp.484-495, 2016.

[27] Manohar Singh, B.K. Panigrahi, A.R. Abhyankar and Swagatam Das, "Optimal coordination of directional overcurrent relays using informative differential evolution algorithm", Electric Power and Energy Systems, vol. 5, pp.269-276, 2014.

[28] A. Fadhel Albasri, R. Ali Alroomi and H. Jawad Talaq, "Optimal coordination of directional overcurrent relays using Bio-geography based optimization algorithms", 
IEEE Transaction on Power Systems, vol. 30, no. 4, pp.1810-1820, 2015.

[29] S.S. Gokhale and V.S. Kale, "An application of a tent map initiated Chaotic Firefly algorithm for optimal overcurrent relay coordination", Electric Power and Energy Systems, vol. 78, pp.336-342, 2016.

[30] M. Muhammad Aman, B. Ghauth Jasmon, Abdul Halim Abu Bakar and et al, "Graph theory-based radial load flow analysis to solve the dynamic network reconfiguration problem", International Transactions on Electrical Energy Systems, DOI:10.1002/etep. 2108, 2015.

[31] Hongwei Li, Wenjin Mao, Anan Zhang and Chao Li, "An improved distribution network reconfiguration method based on minimum spanning tree algorithm and heuristic rules", Electric Power and Energy Systems, vol. 82, pp.466-473, 2016.

[32] Liang Che, Mohammad Khodayar and Mohammad Shahidehpour, "Adaptive Protection System for Microgrids: Protection practices of a functional microgrid system", IEEE Electrification Magazine, vol. 2, no. 1, pp. 66-80, 2014.

[33] Chowdhury, Sunetra, and Peter Crossley, "Microgrids and active distribution networks", The Institution of Engineering and Technology, 2009

[34] S.A. Hosseini, H.A. Abyaneh, S.H.H. Sadeghi, F. Razavi and A. Nasiri, "An overview of microgrid protection methods and the factors involved" Renewable and Sustainable Energy Reviews, vol. 64, pp.174-186, 2016.

[35] J. Kennedy, P. Ciufo and A. Agalgaonkar, "A review of protection systems for distribution networks embedded with renewable generation", Renewable and Sustainable Energy Reviews, vol. 31, no. 58, pp.1308-17, 2016.
[36] L. Mu, H. Han, B. Jiang and W. Guo, "Microgrid protection based on principle of fault location", IEEJ Transactions on Electrical and Electronic Engineering, vol. 11, no.1, pp.30-5, 2016.

[37] C. Mahieux, A. Oudalov, "Microgrids enter the mainstream", Renewable Energy Focus, vol. 17, no.2:702, 2016.

[38] Z. Akhtar and M.A. Saqib, "Microgrids formed by renewable energy integration into power grids pose electrical protection challenges", Renewable Energy, vol. 99, pp. 148-57.

[39] S. Mirsaeidi, D.M. Said, M.W. Mustafa, M.H. Habibuddin and K. Ghaffari, "Modeling and simulation of a communication-assisted digital protection scheme for micro-grids", Renewable and Sustainable Energy Reviews, vol. 57, pp.867-878, 2016.

[40] Abbas Saberu Noghabi, and Javad Sadeh, "Considering Different Network Topologies in Optimal Overcurrent Relay Coordination Using a Hybrid GA", IEEE Trans. Power Delivery, vol. 24, No. 4, pp. 1857-1863, 2009.

[41] Urdaneta, A.J., Restrepo, H., Marquez, and S., Sanchez, J., " Coordination of Directional Relays Timing Using Linear Programming”, IEEE Trans. Power Delivery, vol. 11, No. 1, pp. 122-129, 1996.

[42] Prashant Prabhakar Bedekar, and Sudhir Ramakrishna Bhide., "Optimal coordination of directional overcurrent relays using Hybrid GA-NLP Approach", IEEE Trans. Power Delivery, vol. 26, No. 1, pp. 109-119, 2011.

[43] Gupta A, Varshney A, Swathika OG, Hemamalini S. "Dual Simplex Algorithm Aided Adaptive Protection of Microgrid". 2015 International Conference on Computational Intelligence and Communication Networks (CICN),1505-1509. 